\title{
Student Perceptions of Effectiveness of Case-Based Learning in Orthodontic Education
}

\author{
Zhenhua Yang, Yin Ding, Zuolin Jin and Fang Jin*
}

State Key Laboratory of Military Stomatology, Department of Orthodontics, School of Stomatology, Fourth Military Medical University, Xi'an, Shaanxi 710032, People's Republic of China

\begin{abstract}
Background: Teacher-centered education dominates dental education in China. This report introduced the redesign of an orthodontic course previously delivered in a traditional lecture format into a case-based and studentcentered learning format that focuses on improving students' ability in clinical problem-solving and decision making skills.

Methods: Thirty five dental students at the fourth year of a five-year B.D.S. program met in a ten-period series of seminars. Case details with relevant diagnostic records were provided to each student ahead of time. A diagnostic worksheet was used to guide students through the analytical process to develop the diagnosis and treatment plan. Students took turns leading the discussion at each seminar. Instructors served as facilitators and evaluators. Following the last session, a questionnaire was distributed to each student to evaluate the case-based learning program.

Results: Responses from students revealed that the case-based orthodontic course was well received. Students commented favorably upon improvement in the aspects of problem lists, diagnosis and treatment planning.

Conclusion: It was our initial attempt of using case-based learning format often used in postdoctoral dental education as a curriculum innovation in undergraduate orthodontic education. Our pilot investigation indicated that CBL is worthy of wide use and could be applied in multilevel dental education to develop the dental student's knowledge and skill in comprehensive patient evaluation and diagnosis in preparation for treatment planning.
\end{abstract}

Keywords: Case-based learning, dental education, orthodontic education, questionnaire, undergraduate.

\section{INTRODUCTION}

In China, for many years dental students have been accustomed to the traditional teacher-centered teaching model in which students are merely passively listening to an instructor's lecture. It is generally believed that such traditional lecture courses are not conducive of being engaged in complex thinking and reasoning that is needed for clinical practice [1]. Orthodontic education of five-year B.D.S. (bachelor's degree in stomatology) program in most dental schools of China is mainly designed to provide knowledge in identifying and evaluating dentofacial anomalies in the primary, mixed, and permanent dentitions as well as further understanding of the basic principles and techniques of corresponding orthodontic treatment modalities. However, limited curriculum time and clinical probation is difficult in creating a meaningful learning experience and makes students have rare exposure to the broad range of existing clinical situations [2]. Orthodontic faculty members have been put in a dilemma scenario struggling to balance an enormous load of information conveyed to students with preparing them to enter the clinical setting.

*Address correspondence to this author at the 145 West Changle Road, Xi'an, Shaanxi 710032, People's Republic of China; Tel: +86-29-84776138; E-mail: jinfang@fmmu.edu.cn
Case-based learning was described as a valuable epistemic learning process by which students received basic knowledge from textbooks and lectures and applied it to patient care [3-5]. Different from problem-based learning which has been successfully introduced in many dental schools in China to overcome some of the shortcomings of the traditional curriculum, case-based learning has unique features. In problem-based learning, the problem drives learning by positively collecting and organizing information while in case-based learning, cases serve as a tie to put learning of the basic sciences into realistic clinical contexts $[3,6-10]$. Students are required to recollect previously learned knowledge to solve real clinical cases [11, 12]. Although not as helpful as comprehensive clinical experience, a case-based learning approach can help students practice developing problem lists and making diagnoses of a wide variety of occlusal abnormalities, many of which may not be seen during very limited probation time [3]. So comparatively, case-based learning may make students more prepared to perform in a clinical setting while enhances their understanding of previously learned basic theories, which is of particular importance for students who are going to start their internship at the last year of a five-year B.D.S. program $[13,14]$. In the past few years, case-based learning has been successfully used in orthodontic teaching in School of Stomatology, Fourth Military Medical University and obtained a positive feedback. 
The aim of this study is to introduce how a conventional lecture course was redesigned using a new case/seminarbased teaching and learning model. Orthodontic treatment of malocclusions was chosen as the learning subject. Full records of typical cases were provided to students for practicising making diagnosis and developing problemsolution lists. Using case study material, students were expected to earn an experiential learning experience that mimics the clinical setting. Student perceptions of the course were sought. Our ultimate goal is to shift from traditional lecture-based education (LBE) to a new case- and seminarbased learning format and student-centered instructional models to resemble a near-real clinical scenario achieving the kind of learning that eases the transition of the clinical setting upon externship and graduation.

\section{MATERIALS AND METHODS}

This case-based learning model was introduced in the orthodontic course in the spring semester of 2013 for 35 dental students at the fourth year of a five-year B.D.S. program. Official approval from the university's Institutional Review Board (IRB) for this study was given prior to its start. Before taking this course, the students had taken courses on craniofacial growth and development, etiology and classification of malocclusion, radiographic cephalometry, orthodontic examination and diagnosis, biomechanics and orthodontic appliances and techniques. The course aims to introduce the basic principles of orthodontic treatment of malocclusions and enhance students' experience in practicing creating problem lists, making diagnosis and, based on those problem lists, further developing a treatment plan.

Common malocclusions including class I, class II and class III malocclusions were discussed in this course. Major topics covered comprise the following: dental crowding, bimaxillary protrusion, anterior crossbite, posterior crossbite, scissors bite, deep overjet, deep overbite, open bite, cleft of lip and palate and orthognathic surgery. An example of subtopics under the major topic "deep overbite" included etiology, general features, classifications, diagnosis and treatment of deep overbite. Accordingly, corresponding with the above each topic, one typical case with full records including study models, panoramic and cephalometric radiographs, facial and intraoral photographs, and clinical examination details were provided to students. A total of 10 typical cases treated by faculty members involved in this course were selected and discussed in the course.

Case-based instruction is a problem-based instructional method in which small groups of students are presented with a clinical case to study, discuss, and "solve." In this study, thirty five students were divided into 5 groups with each group of 7 students. They met in a ten-period series of seminars for ten major topics. For advance preparation, the topics with corresponding set of diagnostic case records were distributed to students ahead of time. Identical information and case details were provided to all students. A diagnostic worksheet was used to guide students through the analytical process to develop the diagnosis and treatment plan. At each seminar, one group was pre-assigned to lead the discussion with a short lecture first, followed by a case discussion with complete diagnosis and treatment options provided. Students were supported to make their treatment planning with the aid of literature review and evidence-based dentistry. The others were expected to be free to provide alternative diagnosis and treatment methods, thereby enhancing their understanding of the benefits and drawbacks of the treatment plans selected. Each group and each student within the group took turns leading and participating in the group discussion, so that every team and every person would undertake both the role of leader and participator. The primary responsibilities of the instructors were to facilitate rather than to guide the discussion. One case was evaluated per period and each oneperiod seminar ended with the instructor summarizing the relevant details.

Questionnaire design was based on the one that was used in Carly T. McKenzie`s study to assess students' perceptions of the redesigned course [15]. Changes were made in some of the questions mainly according to the feedback from faculties and students previously engaged in the course. The questionnaire was divided into three parts: students' perceptions of the course's professional and communicative benefit and facilitator performance. The students ranked their agreement with items on a scale of ranging from 1 to 5 with $1=$ strongly disagree and $5=$ strongly agree. No one reported to have trouble understanding the survey questions.

\section{RESULTS}

The survey was conducted at the end of the course. Survey answers were anonymous. The overall response rate was 100 percent. The scoring breakdown of each question is listed in Tables 1-3. The mean score of all questions was above 3 (agreement), indicating that the case-based learning format won students' high acceptance. First, students' perceptions of professional benefit were examined (Table 1). A high percentage of students responded with scores of 4 or 5. More than $85 \%$ of students believed that case-based learning helped them 'interpret a patient's medical and dental data", "learn how to develop a problem list and diagnosis", "have a clear understanding of the basic principles of orthodontic treatment plan" and "apply previous knowledge better than lecture", awarding a score of 4 or 5 , which exactly accords with major objective of the course. However, $40 \%$ of students awarded a score of 3 or less to question 5 "case-based learning improved their learning efficiency", though most of students believed that "Case-based learning is helpful in promoting self-learning". The feedback from students indicated that some of them thought that their background in orthodontics was not very thorough and partly lecture would have allowed more effective learning.

Next, students' perceptions of communicative benefits were examined (Table 2). Students' mean scores indicated that this student-centered learning and teaching model increased communication and interaction between students and teachers as expected. The scores were a little lower in aspects of being able to communicate a treatment plan clearly and concisely, which received a mean score of 3.7. This was because students believed that previous orthodontic courses were not given in the same teaching method. So at times the cases seemed a little advanced for them especially when they were not well prepared from previous courses. 
Table 1. Students' perceived professional benefits $(n=35)$.

\begin{tabular}{|c|c|c|c|c|c|c|c|}
\hline \multicolumn{2}{|r|}{ Questions } & \multicolumn{2}{|c|}{$\begin{array}{c}\% \\
\text { Strongly } \\
\text { Disagree }\end{array}$} & - & \multicolumn{2}{|c|}{$\begin{array}{c}\% \\
\text { Strongly } \\
\text { Agree }\end{array}$} & \multirow{3}{*}{$\begin{array}{c}\text { Class } \\
\text { Mean } \\
4.5\end{array}$} \\
\hline & & \multirow[t]{2}{*}{1} & \multirow[t]{2}{*}{2} & 3 & 4 & 5 & \\
\hline 1. & Case-based learning helped me interpret a patient's medical and dental data. & & & $5.8 \%$ & $37.1 \%$ & $57.1 \%$ & \\
\hline 2. & Case-based learning helped me learn how to develop a problem list and diagnosis. & & & $8.6 \%$ & $60 \%$ & $31.4 \%$ & 4.2 \\
\hline 3. & $\begin{array}{l}\text { Case-based learning helped me have a clear understanding of the basic principles of } \\
\text { orthodontic treatment plan. }\end{array}$ & & & $14.3 \%$ & $54.3 \%$ & $31.4 \%$ & 4.2 \\
\hline 4. & Case-based learning helped me learn the content in a more comprehensive way. & & $3 \%$ & $5.7 \%$ & $68.5 \%$ & $22.8 \%$ & 4.1 \\
\hline 5 . & Case-based learning improved my learning efficiency. & $5.8 \%$ & $17.1 \%$ & $20 \%$ & $45.7 \%$ & $11.4 \%$ & 3.4 \\
\hline 6. & Case-based learning is helpful in promoting self-learning. & & $3 \%$ & $11.4 \%$ & $28.5 \%$ & $57.1 \%$ & 4.4 \\
\hline 7. & Case-based learning helped me apply previous knowledge better than lecture. & & & $5.7 \%$ & $22.8 \%$ & $71.4 \%$ & 4.7 \\
\hline 8. & Case-based learning encouraged my interest in orthodontics. & & & & $14 \%$ & $86 \%$ & 4.9 \\
\hline
\end{tabular}

Table 2. Students' perceived communicative benefits $(n=35)$.

\begin{tabular}{|c|c|c|c|c|c|c|c|}
\hline & \multirow[t]{2}{*}{ Questions } & $\begin{array}{c}\% \\
\text { Strongly } \\
\text { Disagree }\end{array}$ & \multicolumn{2}{|c|}{--} & \multicolumn{2}{|c|}{$\begin{array}{c}\% \\
\text { Strongly } \\
\text { Agree }\end{array}$} & \multirow[t]{2}{*}{$\begin{array}{l}\text { Class } \\
\text { Mean }\end{array}$} \\
\hline & & 1 & 2 & 3 & 4 & 5 & \\
\hline 1. & I understand what makes small groups operate effectively. & & & $2.9 \%$ & $31.4 \%$ & $65.7 \%$ & 4.6 \\
\hline 2. & I am confident in my ability to contribute effectively to the team. & & & $5.8 \%$ & $25.7 \%$ & $68.5 \%$ & 4.3 \\
\hline 3. & $\begin{array}{l}\text { I am confident in discussing treatment plans with my classmates and teachers } \\
\text { (instructors). }\end{array}$ & & $8.6 \%$ & $17.1 \%$ & $40 \%$ & $34 \%$ & 4.0 \\
\hline 4. & I can communicate aspects of a treatment plan clearly and concisely. & $5.8 \%$ & $11.4 \%$ & $11.4 \%$ & $48.6 \%$ & $22.8 \%$ & 3.7 \\
\hline
\end{tabular}

Finally, students' perceptions of facilitator performance were analyzed (Table 3). The overall assessment of facilitator s' performance was positive. The evaluation item about "giving useful information feedback" was relatively lower, with a mean score of 3.5.

\section{DISCUSSION}

Regular orthodontic education in China began in the 1970 `s [2]. In the past few decades, with increasing communication with dental schools of other countries, some new teaching concepts and methods were being introduced into Chinese schools to accommodate the growing needs of dental education [16-18]. As a part of a program called "internationalized education" which was carried out about 4 years ago in School of Stomatology, Fourth Military Medical University, case-based learning was a favorable attempt that we made in orthodontic education. We picked 35 fourth-year dental students who were going to enter the internship training program soon and explored the effects of the case-based learning course. The results of our evaluation revealed that the case-based orthodontic course was well accepted by students. The responses to the questionnaire indicated that case-based learning format enhanced students diagnostic skills and treatment thinking, which is the right purpose of this course being redesigned. Thus as an educational method to obtain an experiential learning experience that mimics the clinical environment, the present course is undoubtedly successful, at least from the student's point of view.

Table 3. Students' perceptions of facilitator performance $(n=35)$.

\begin{tabular}{|c|c|c|c|c|c|c|c|}
\hline & \multirow[t]{2}{*}{ Questions } & \multicolumn{2}{|c|}{$\begin{array}{c}\% \\
\text { Strongly } \\
\text { Disagree }\end{array}$} & -- & \multicolumn{2}{|c|}{$\begin{array}{c}\% \\
\text { Strongly } \\
\text { Agree }\end{array}$} & \multirow[t]{2}{*}{$\begin{array}{l}\text { Class } \\
\text { Mean }\end{array}$} \\
\hline & & 1 & 2 & 3 & 4 & 5 & \\
\hline 1. & The facilitator enlightens me during my case preparation. & $2.9 \%$ & $2.9 \%$ & $11.4 \%$ & $34.2 \%$ & $48.6 \%$ & 4.2 \\
\hline 2. & The facilitator is an effective manager of the group's discussion. & & & $8.6 \%$ & $20 \%$ & $71.4 \%$ & 4.6 \\
\hline
\end{tabular}


As a branch of dentistry, orthodontics is an experiencebased discipline, in which knowledge or experiences accumulated from previous cases play a very important role in developing the ability for accurate diagnosis and treatment $[19,20]$. Although case-based learning is more frequently applied in postdoctoral dental education, the current study has demonstrated the feasibility of the application of casebased teaching in undergraduate dental education. It is important that students who attend the course have some background in orthodontics. The students we picked in this study almost have finished their learning of orthodontic basics such as craniofacial growth and development, diagnosis and examination and orthodontic appliances and techniques. In spite of this, a short lecture in the beginning of each case seminar still might be necessary to help students comb through the knowledge they've learned. Thus enormous amount of information could be conveyed in a manner that allowed effective learning and better understanding. We are also considering having case-based learning winding through all areas of orthodontic teaching with differential emphasis on the ratio of lecture $v s$ cases in the future. For example, more lecture $v s$ cases in craniofacial growth and development, half lecture $v s$ half cases in diagnosis and examination and less lecture vs cases in orthodontic treatment of common malocclusions. Once students are well prepared from previous courses, they won't lose their heads while facing cases in a near-real clinical setting.

In case-based learning, both construction of cases and instructors' skill are important [21,22]. The clinical cases were regarded as a key element that would be helpful in developing the clinical skills of students and in compensating the lack of clinical exposure in the undergraduate orthodontic curriculum. The cases we selected were multifaceted and supposed to reflect typical clinical scenarios. It should be noted that cases were not given with the objective of supporting factual information but rather with a purpose to promote independent learning, clinical problem solving as well as decision making by using knowledge from class. In this study, after the end of the course the students commented favorably upon improvement in the aspects of problem lists, diagnosis and treatment planning. Instructors were supposed to facilitate students' discussion, guide their clinical reasoning method, and help them to summarize key learning objectives. It is necessary to underline that after each seminar, students were encouraged to be free to inquire and investigate unfamiliar concepts. The instructors should allocate specific time to be responsible for providing uniform feedback.

The current study has limitations. It relied on a relatively small sample and only one course at one dental school, which in a sense allowed for less power to aid in broad application and generalizability. The survey is helpful in measuring perception, but is insufficient for evaluating actual gaining of knowledge and skills. Maybe a more objective assessment such as actual learning as defined by examination performance is necessary for evaluation.

\section{CONCLUSION}

This report introduced the redesign of an orthodontic course previously delivered in a traditional lecture format into a case-based and student-centered learning format that focuses on improving students' ability in clinical problemsolving and decision making skills. It was our initial attempt of adopting new teaching concept as a curriculum innovation in orthodontics. Our pilot investigation indicated that CBL is worthy of wide use and could be applied in multilevel dental education to develop the dental student's knowledge and skill in comprehensive patient evaluation and diagnosis in preparation for treatment planning.

\section{CONFLICT OF INTEREST}

The authors confirm that this article content has no conflict of interest.

\section{ACKNOWLEDGEMENTS}

The authors would like to acknowledge all faculty members in Department of Orthodontics, School of Stomatology, Fourth Military Medical University who participated in the implementation of case-based learning.

\section{REFERENCES}

[1] Tayem YI. The impact of small group case-based learning on traditional pharmacology teaching. Sultan Qaboos Univ Med J 2013; 13(1): 115-120.

[2] Yeweng SJ, Huang SF, Ren LJ. Orthodontics in China. J Orthod 2002; 29(1): 62-5.

[3] Engel FE, Hendricson WD. A case-based learning model in orthodontics. J Dent Educ 1994; 58(10): 762-7.

[4] Johnson JA, Kopp KC, Williams RG. Standardized patients for the assessment of dental students' clinical skills. J Dent Educ 1990; 54(6): 331-3.

[5] Chiodo GT, Bullock WW, Creamer HR, Rosenstein DI. An application of the Patient-Oriented Problem-Solving (POPS) system. J Dent Educ 1991; 55(5): 327-31.

[6] Norman GR. Problem-solving skills, solving problems and problem-based learning. Med Educ 1988; 22(4): 279-86.

[7] Fincham AG, Shuler CF. The changing face of dental education: the impact of PBL. J Dent Educ 2001; 65(5): 406-21.

[8] Bearn DR, Chadwick SM. Problem-based learning in postgraduate dental education: a qualitative evaluation of students' experience of an orthodontic problem-based postgraduate programme. Eur J Dent Educ 2010; 14(1): 26-34.

[9] Nadershahi NA, Bender DJ, Beck L, Lyon C, Blaseio A. An overview of case-based and problem-based learning methodologies for dental education. J Dent Educ 2013; 77(10): 1300-5.

[10] Op't Holt TB. Problem-based and case-based learning in respiratory care education. Respir Care Clin N Am 2005; 11(3): 489-504.

[11] Ilguy M, Ilguy D, Fisekcioglu E, Oktay I. Comparison of casebased and lecture-based learning in dental education using the SOLO taxonomy. J Dent Educ 2014; 78(11): 1521-7.

[12] Khosa DK, Volet SE, Bolton JR. Making clinical case-based learning in veterinary medicine visible: analysis of collaborative concept-mapping processes and reflections. J Vet Med Educ 2014; 41(4): 406-17.

[13] McMahon MA, Christopher KA. Case study method and problembased learning: utilizing the pedagogical model of progressive complexity in nursing education. Int J Nurs Educ Scholarsh 2011; 8: Article 22.

[14] Sharkey L, Overmann J, Flash P. Evolution of a course in veterinary clinical pathology: the application of case-based writing assignments to focus on skill development and facilitation of learning. J Vet Med Educ 2007; 34(4): 423-30.

[15] McKenzie CT. Dental student perceptions of case-based educational effectiveness. J Dental Educ 2013; 77(6): 688-94.

[16] Huang C, Bian Z, Tai B, Fan M, Kwan CY. Dental education in Wuhan, China: challenges and changes. J Dent Educ 2007; 71(2): 304-11. 
[17] Zhang SY, Zheng JW, Yang C, et al. Case-based learning in clinical courses in a Chinese college of stomatology. J Dent Educ 2012; 76(10): 1389-92.

[18] Du GF, Li CZ, Shang SH, Xu XY, Chen HZ, Zhou G. Practising case-based learning in oral medicine for dental students in China. Eur J Dent Educ 2013; 17(4): 225-8.

[19] Keim RG, Sinclair PM. Orthodontic graduate education survey, 1983-2000. Am J Orthod Dentofacial Orthop 2002; 121(1): 2-8.
[20] O'Brien K. Undergraduate orthodontic education: what should we teach rather than what can we teach? Br J Orthod 1997; 24(4): 3334.

[21] Kassebaum DK, Averbach RE, Fryer GE, Jr. Student preference for a case-based vs. lecture instructional format. J Dent Educ 1991; 55(12): 781-4.

[22] Hay PJ, Katsikitis M. The 'expert' in problem-based and case-based learning: necessary or not? Med Educ 2001; 35(1): 22-6.

(C) Yang et al.; Licensee Bentham Open.

This is an open access article licensed under the terms of the Creative Commons Attribution Non-Commercial License (http://creativecommons.org/licenses/by-nc/ 3.0/) which permits unrestricted, non-commercial use, distribution and reproduction in any medium, provided the work is properly cited. 